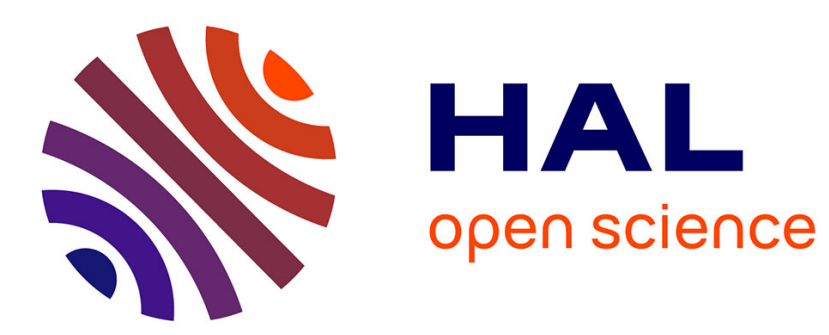

\title{
BUMPER DEBRIS CLOUD STRUCTURE ESTIMATED BY SHOCK CALCULATIONS
}

\author{
S. Bless
}

\section{To cite this version:}

S. Bless. BUMPER DEBRIS CLOUD STRUCTURE ESTIMATED BY SHOCK CALCULATIONS. Journal de Physique IV Proceedings, 1991, 01 (C3), pp.C3-903-C3-908. 10.1051/jp4:19913127 . jpa00249932

\section{HAL Id: jpa-00249932 https://hal.science/jpa-00249932}

Submitted on 1 Jan 1991

HAL is a multi-disciplinary open access archive for the deposit and dissemination of scientific research documents, whether they are published or not. The documents may come from teaching and research institutions in France or abroad, or from public or private research centers.
L'archive ouverte pluridisciplinaire HAL, est destinée au dépôt et à la diffusion de documents scientifiques de niveau recherche, publiés ou non, émanant des établissements d'enseignement et de recherche français ou étrangers, des laboratoires publics ou privés. 
Colloque C3, suppl. au Journal de Physique III, Vol. 1, octobre 1991

\title{
BUMPER DEBRIS CLOUD STRUCTURE ESTIMATED BY SHOCK CALCULATIONS
}

\author{
S.J. BLESS \\ University of Dayton, Research Institute, 300 College Park, \\ Dayton, Ohio 45469-0182, U.S.A
}

\begin{abstract}
A relatively simple shock analysis is developed for hypervelocity impact onto spacecraft bumpers. The example treated is a copper disc striking aluminum. The shape of the debris cloud scales with the impact velocity and is determined only by the shock impedances of the projectile and bumper materials. The bumper and projectile debris clouds separate. The peak bumper debris velocity exceeds the impact velocity; the peak projectile debris velocity is equal to the impact velocity. The differential motion of the front and rear of the projectile cloud causes spall in the projectile.
\end{abstract}

\section{Introduction}

Use of sacrificial bumpers to protect space vehicles from impact of natural and man-made particles has been investigated for several years/1-3/. Early work mainly focused on particles whose density was similar to the bumper, such as glass or aluminum striking aluminum. These studies have led to several analytical models that described debris clouds as expanding hollow spherical shells/4.6/.

Piekutowski/7-8/ has shown that when the density of the particle is quite different from the bumper, the debris cloud has considerably more structure than predicted by spherical models. These findings have recently been confirmed by other investigators ${ }^{19-10 /}$.

Fig. 1, for example, illustrates a cloud from a copper disc striking an aluminum bumper at $6.53 \mathrm{~km} / \mathrm{s}$. There is a high speed conical-shaped aluminum outer cloud, followed by a slower and denser copper cloud that is roughly diamond shaped.

Analysis of debris clouds such as Fig. 1 was presented in $18 /$. There it was shown that for copper discs striking aluminum bumpers: (a) the particles in the debris cloud do not interact with one another once the cloud is formed. (b) The shape of the cloud does not depend on the size scale of the experiments, for projectile masses from 1 to $10 \mathrm{~g}$. (c) The shape of the cloud is only weakly dependent on impact velocity, for velocities from 3.45 to $6.53 \mathrm{~km} / \mathrm{s}$. (d) The velocity of the cloud scales with impact velocity. (e) The cloud is only affected by the material that is "punched out" by the projectile, not by bumper material adjacent to the impact. 


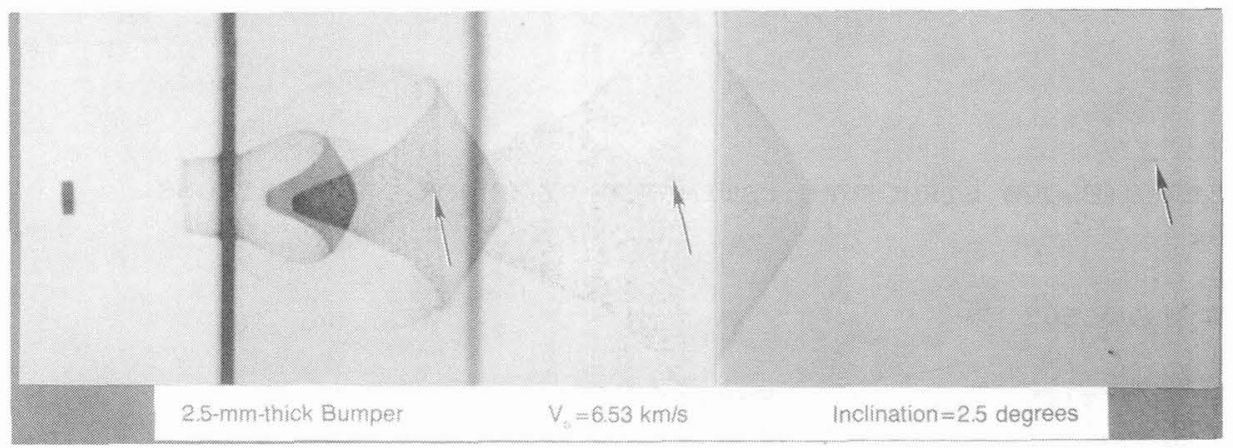

Fig 1. Radiograph from shot 863 at $6.53 \mathrm{~km} / \mathrm{s}$, showing structure of the debris cloud. Arrow points to leading edge.

\section{Simple model}

Compared to earlier work with spherical projectiles, the disc-shaped projectiles used in/7-8/ also result in an impact process that is easier to analyze in terms of fundamental shock interactions. Fig. 2 is a simplified sketch of the debris cloud shown in Fig. 1. Fig. 3 is a sketch of shock interactions in the bumper and projectile, assuming no impact yaw or obliquity, and an impact velocity of $6.3 \mathrm{~km} / \mathrm{s}$. Fig. 3 is drawn from a "Lagrangian" perspective, in which the coordinate system is attached to the particles; thus, there is no movement of material shown in Fig. 3. Fig. 4 is an " $x, t$ " diagram for the idealized shock interactions along the center line of the impact, ignoring off axis effects. Interaction regions shown in the figures are discussed below.

Before impact the bumper and the target are in states $A_{2}$ and $A_{1}$, respectively. The peak shock states of the bumper and projectile after impact are obtained from "impedance match" solutions/11-12/. This process is illustrated in Fig. 5, which is a stress-particle velocity diagram (not to scale) for the shock interactions shown in Fig. 4. The lines labelled $P$ and $B$ in Fig. 5 are projectile Hugoniots and bumper Hugoniots, respectively. (Ref. data for Hugoniots of engineering materials can be found in 111,13/). The slopes of the Hugoniot curves in Fig. 5 are equal to the shock impedances of the projectile and bumper, which in the example are assumed constant. In drawing Fig. 5, we also ignored the relatively small difference between shock paths (e.g. Hugoniots) and unloading paths (isentropes).

Before impact, the bumper particle velocity is $u=0$, and the projectile particle velocity is $u=v_{0}$. The initial shock brings both the bumper and projectile to velocity $u_{s}$, where $0<u_{s}<v_{0}$. Both the stress and particle velocity of the projectile and the bumper are the same here. The B Hugoniot is footed at the origin, because the bumper is initially at rest; the projectile Hugoniot is footed at the impact velocity, $V_{0}$, because this is the particle velocity when the projectile is at zero stress. The intersection gives the point where $u=u_{s}$. This is state $B$. The change in particle velocity associated with the peak shock stress in the bumper is,

$$
\Delta u_{b}=u_{s}
$$

while the change in particle velocity associated with the peak shock in the projectile is, 


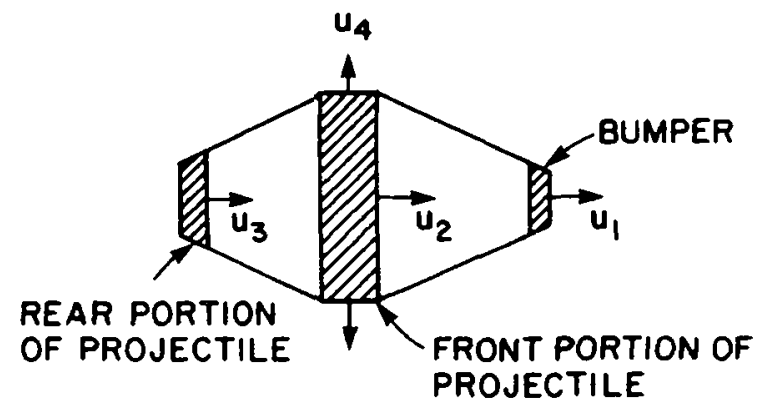

Fig 2. Sketch of debris cloud.

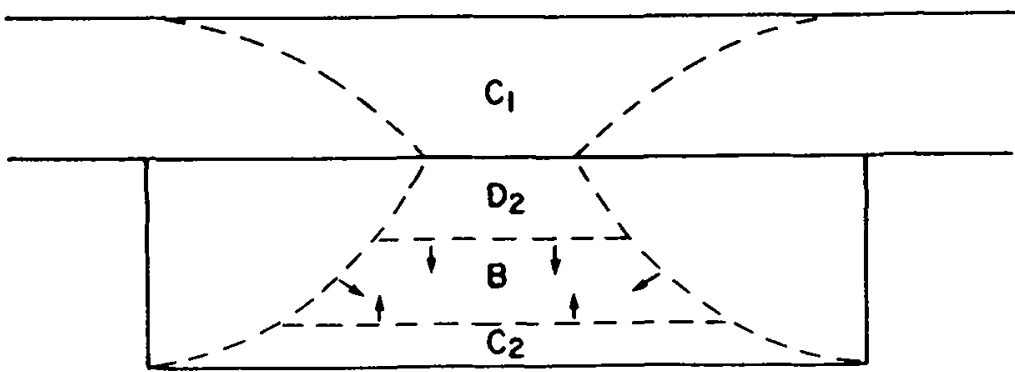

Fig. 3. Wave fronts in impact of copper onto aluminum at $6.35 \mathrm{~km} / \mathrm{s}$. $0.45 \mu \mathrm{s}$ after impact.

$$
\Delta u_{p}=v_{6}-u_{\xi} \cdot
$$

Velocity $u_{1}$ occurs when the shock wave in the bumper reflects from the rear surface of the bumper, bringing that region to zero stress. This is state $C_{1}$. It can be seen by inspection of Fig. 5 that in state $C_{1}$,

$$
u_{1}=2 u_{s} .
$$

Velocity $u_{3}$ occurs when the shock wave in the projectile reflects from the rear surface of the projectile, again resulting in a stress-free region (state $C_{2}$ ). Again, it can be seen from Fig. 5 that,

$$
u_{3}=u_{s}-\Delta u_{p}=2 u_{s}-v_{0} \text {. }
$$

For the geometry that we are considering, as shown in Fig. 4, the release wave in the bumper arrives at the projectile/bumper interface before the release wave in the projectile. Since the projectile has a higher shock impedance than the bumper, the bumper separates from the projectile at this point. The particle velocity of the entire bumper is now $u_{1}$. However, the particle velocity of the projectile (state $D$ ) which is denoted $u_{2}$, results from a release wave from the peak shock state B. Hence,

$$
\mathrm{u}_{2}=\mathrm{v}_{0} \text {. }
$$




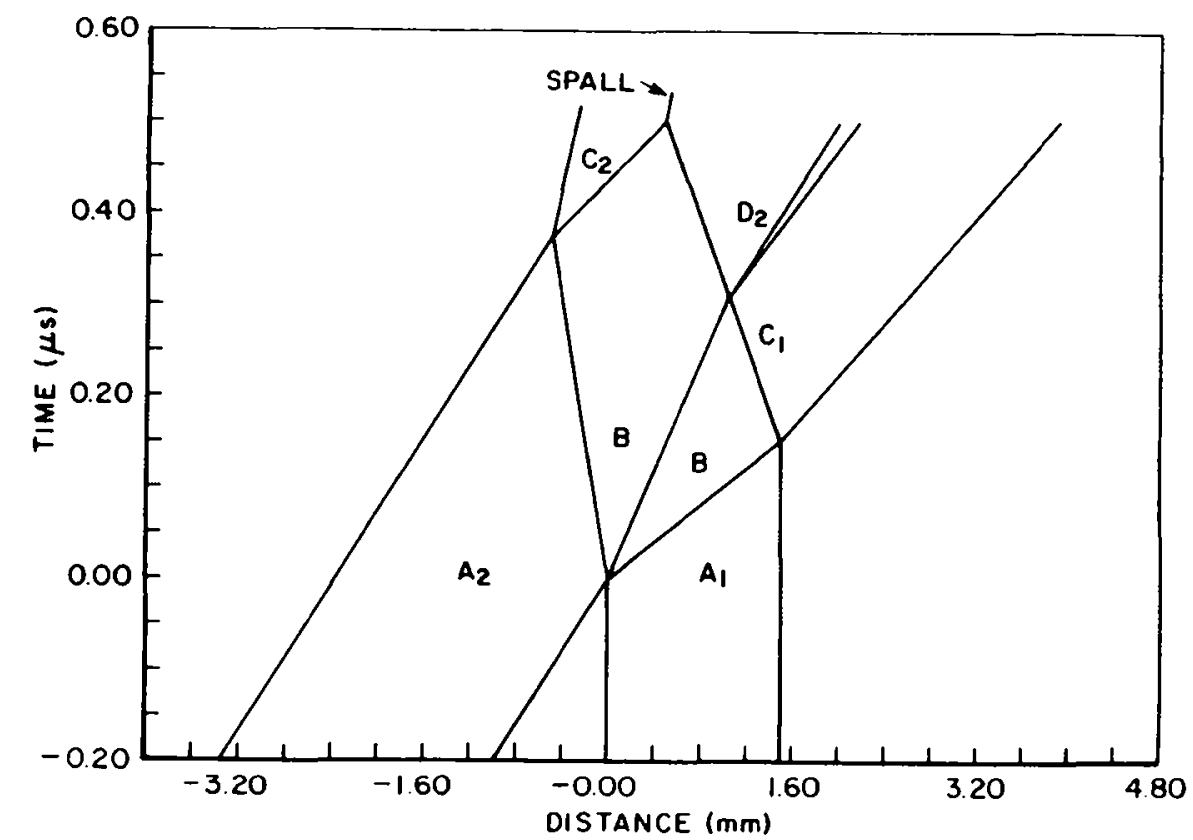

Fig. 4. (x,t) Diagram for impact of $2 \mathrm{~mm}$ copper disc onto $1.5 \mathrm{~mm} \mathrm{Al}$ bumper. (Impact occurs at $(0,0)$.)

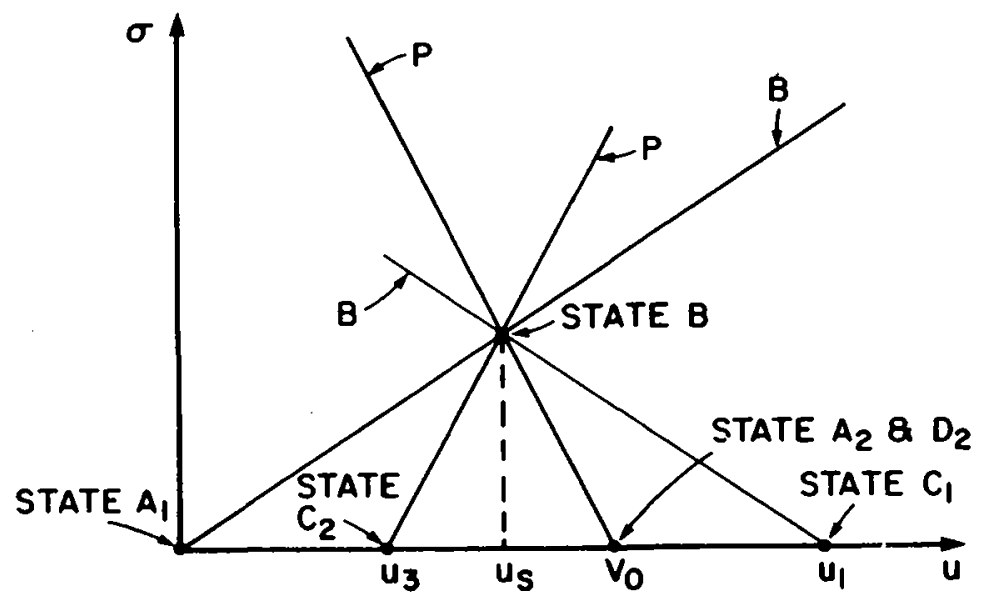

Fig. 5. Impedance match diagram to give shock and release states in the impact shown in Figure 4.

When the two release waves in the projectile intersect, a spall results. The materials on either side of the spall plane are moving at velocities $v_{0}$ and $u_{3}$.

There is also an off-axis release. As shown in Figure 3, release waves move into the shocked region from the periphery of the impact. The change in velocity associated with these release waves is $\Delta u_{b}$ in the 
bumper, and $\Delta \mathrm{u}_{\mathrm{p}}$ in the projectile. These expansions account for the radial velocities of the debris cloud. Release in the bumper is complicated by the contiguous material next to the impact site. In the projectile, radial expansion occurs with velocity $u_{4}$ given by,

$$
u_{4}=\Delta u_{p}=v_{0}-u_{s} \text {. }
$$

The conical shape of the debris cloud results from the transition from material that is shocked and relieved on axis, resulting in the velocities given by Eq. 3-5, to material that is first relieved from the sides, receiving a vector velocity that has an axial component $u_{s}$ and a radial component given by $\mathrm{Eq} .6$.

According to this analysis, the shape of the inner and outer debris cloud is determined only by the peak shock particle velocity $u_{s}$. The value of $u_{s}$ is a function only of the impact velocity and Hugoniots of the bumper and projectile. For most combinations of materials $u_{s}$ is effectively linearly proportional to $V_{0}$.

\section{Comparisons with experimental data}

Predictions of calculations with this model are compared with experimentally observed cloud dimensions reported in/8!. The results are given in Table 1. Data precision is generally about \pm 3 percent. It can be seen that the agreement is generally excellent.

Table 1. Comparison of data and model for Cu striking aluminum.

\begin{tabular}{|c|c|c|c|c|c|c|c|c|c|c|c|}
\hline \multicolumn{3}{|c|}{ IMPAC I } & \multicolumn{4}{|c|}{ MLASUREO (REFERENCE 8 ) } & \multicolumn{4}{|c|}{ MOOLL } & 211,11 \\
\hline Shot & $v_{0}$ & Yaw & $u_{1}$ & $u_{2}$ & $u_{3}$ & $u_{4}$ & $u_{1}$ & $u_{2}$ & $u_{3}$ & $u_{4}$ & $u_{1}$ \\
\hline Nunber & $\mathrm{km} / \mathrm{s}$ & $(1)$ & $v_{0}$ & $v_{0}$ & $v_{0}$ & $v_{0}$ & $v_{0}$ & $v_{0}$ & $v_{0}$ & $v_{0}$ & $v_{0}$ \\
\hline 936 & 6.39 & 4.6 & 1.44 & 1.02 & 0.36 & 0.35 & 1.35 & 1.00 & 0.35 & 0.33 & 1.41 \\
\hline 969 & 6.36 & 7.8 & 1.44 & 1.01 & 0.36 & 0.36 & 1.34 & 1.00 & 0.34 & 0.33 & 1.41 \\
\hline 1007 & 6.38 & 10.7 & 1.42 & 0.99 & 0.35 & 0.38 & 1.34 & 1.00 & 0.34 & 0.34 & 1.41 \\
\hline 863 & 6.56 & 2.5 & 1.46 & 0.97 & 0.35 & 0.34 & 1.35 & 1.00 & 0.35 & 0.33 & 1.42 \\
\hline 971 & 3.45 & 2.5 & 1.37 & 0.96 & 0.43 & 0.30 & 1.36 & 1.00 & 0.36 & 0.32 & 1.39 \\
\hline 972 & 4.85 & 4.7 & 1.43 & 0.99 & 0.39 & 0.36 & 1.36 & 1.00 & 0.36 & 0.32 & 1.40 \\
\hline
\end{tabular}

The prediction for leading edge velocity, $u_{1} / V_{0}$, is about 7 percent too low. The prediction for the primary projectile debris, $u_{7} / V_{0}$, is about 1 percent too high. The prediction for the trailing projectile debris, $u_{3} / V_{0}$, is about 6 percent too low on average. Predicted lateral

velocity of the projectile, $u_{4} / v_{0}$, is about 5 percent too low. The trends predicted by the analysis are consistently followed by the data, namely scaling by impact velocity, and $u_{1} \cong 1.3 u_{2}, u_{3} \cong u_{4}$, and the leading projectile debris travels at the impact velocity.

The agreement with measured debris velocities can be improved if we take into account the isentropic release which differs slightly from the Hugoniot. Using the free surface data calculated for copper in'i... reduces the discrepancies in $u_{1} / v_{0}$ to the values shown in the column labelled "Ref. 11". 


\section{Discussion}

This model gives a quantitative account of the debris clouds formed when hypervelocity high impedance flat projectiles strike low impedanc bumpers. It also provides insight into many other scenarios.

When the projectile and bumper are the same material, then the bumper will not rebound off the projectile face. Moreover, $u_{s}=v_{0} / 2$, which will result in a single spherical debris cloud.

When the projectile is spherical, the same processes will occur, but because of the geometry, the maximum values of velocities presented in the previous section may not occur. As shown in $/ 8-9 /$, however, the separation of the debris cloud into bumper and projectile components still occurs.

\section{Acknowledgements}

The author is grateful to Andy Piekutowski for supplying the radial expansion data, to Don Jurick for performing SWAP calculations needed to construct Figures 3 and 4 , and to Alan Hopkins for pointing out the improvement that results when free surface velocity computations from Ref. 11 are employed. This work was sponsored by Acurex Corporation under Subcontract No. AW10072Z; the author appreciates the encouragement provided by contract monitor Mr. Glenn Ormbrek at WPAFB.

\section{References}

1/ GeHRING,J.W., pp High Velocity Impact Phenomena, ed. R. Kinslow, Academic Press (1970).

12/ SWIFT,H.F. and HOPKINS,A.K. J. Spacecraft Rockets 7,73-77, (1970)

13/ ANDERSON,C.E and MULLIN, S.A. Impact Effects of Fast Transient Loadings, Amman et al eds, Balkema, (1988).

/4/ HOLIAN, K.S and BURKETT,M.W., Int. J. Impact Eng. 5,333-341, (1987).

15/ SWIFT,H.F, PREONAS,D.D, and TURPIN,C.W, Rev. SCi. Inst. 4, 746$751,(1970)$.

16/ LAWRENCE,R.J, Shock Compression of Condensed Matter-1989, NorthHolland, (1990).

/7/ PIEKUTOWSKI, A Int. J. Impact Engr. 5,509-518, (1989).

18/ PIEKUTOWSKI, A, Int. J. Impact Engr.10,453-474, (1990).

19/ STILP, A, HOLER, V, SCHNEIDER, E and WEBER, K, Int. J. Impact Engr.10, $543-553,(1990)$.

$110 /$ MOTT, R and GOOD, M, Hypervelocity Impact Symp., San Antonio, TX, 12-14 December (1989).

111/ MCQUEEN, R.G, MARCH,S.P, TAYLOR,J.W, FRITZ,J.N, and CARTER,W.J Higl Velocity Impact Phenomena, R. Kinslow, ed., 1970.

112 ; EVANS,A.G, Erosion, ed. C.M. Preece, Academic Press, 1979.

/13/ LASL Shock Hugoniot Data, ed. MARSH, S.P Univ. of California Press, 1980 . 